\title{
A study on the interaction of feldspar and quartz with mixed anionic/cationic collector
}

\author{
Ismail Ibrahim ${ }^{1 *}$, Hashim Hussin ${ }^{2}$, Khairun Azizi Mohd Azizli ${ }^{3}$ and Md Muzayin Alimon ${ }^{1}$ \\ ${ }^{1}$ Mineral Research Centre, Minerals and Geoscience Department Malaysia, Jalan Sultan Azlan Shah, 31400 Ipoh, Perak, \\ ${ }^{2}$ School of Materials and Mineral Resources Engineering, Engineering Campus, Universiti Sains Malaysia, 14300 Nibong Tebal, Penang. \\ ${ }^{3}$ Chemical Engineering Department, Universiti Teknologi Petronas, Bandar Seri Iskandar, 31750 Tronoh, Perak \\ Received 31 August 2011, Revised 10 November 2011, Accepted 23 November 2011, Available online 1 December 2011
}

\begin{abstract}
Interaction studies of feldspar and quartz with a mixed cationic/anionic collector namely N-tallow 1,3-propylenediamine-dioleate (duomeen TDO) were carried-out. The interaction between collector and minerals has potential to change the surface properties from hydrophilic to hydrophobic. In this study the adsorption behaviour of duomeen TDO on feldspar and quartz was assessed through zeta potential $(\zeta)$ and contact angle $(\Theta)$ measurement as well as with Fourier transformed infra-red (FTIR) spectroscopy. The sample was collected from Apex Granite, Muar, Johor and thus sample characterization were also carried out such as X-ray diffraction (XRD) was used for qualitative analysis and field emission scanning electron microscopy (FESEM) in order to yield useful microscopic information. Zeta-potential results between $\mathrm{pH} 2$ and $\mathrm{pH} 10$ for feldspar and quartz were measured. When the zero negative value of quartz reached $\mathrm{pH} 2$ the separation process of feldspar from quartz was more significant. By gradually adding duomeen TDO, the contact angle of feldspar and quartz were increased leading to enhance hydrophobicity, but decreasing its free energy and components (Lifshitz-van der Waals $\gamma_{s}{ }^{\mathrm{LW}}$, Lewis electron-donor $\gamma_{\mathrm{s}}{ }^{-}$, and Lewis electron-acceptor $\gamma_{\mathrm{s}}^{+}$). FTIR results showed that at various dosages of duomeen TDO, this collector adsorbed on feldspar and quartz surfaces in the bands characteristic of alkyl chains, $v_{\text {as }}\left(\mathrm{CH}_{3}\right), v_{\text {as }}\left(\mathrm{CH}_{2}\right)$ and $v_{\mathrm{s}}\left(\mathrm{CH}_{2}\right)$ groups between region of 3000$2800 \mathrm{~cm}^{-1}$. Moreover the intensity of the alkyl chain bands increased slightly higher for feldspar compared to quartz with increasing initial duomeen TDO concentration. Finally single mineral flotation tests using Hallimond tube were performed and it has been found that feldspar floatability increased with increasing concentration of duomeen TDO.
\end{abstract}

| Adsorption | Feldspar | Quartz | Mixed Collector | Flotation |

® 2011 Ibnu Sina Insitute. All rights reserved. http://dx.doi.org/10.11113/mjfas.v7n2.246

\section{$1.0 \quad$ INTRODUCTION}

Feldspar is a basic raw material used in glass and ceramic industries. In a significant proportion of feldspar ores, Na-feldspar (albite, $\mathrm{NaAlSi}_{3} \mathrm{O}_{8}$ ) and K-feldspar ( $\mathrm{KAlSi}_{3} \mathrm{O}_{8}$, microcline or orthoclase) exist in the same matrix. The basic feldspar structure consists of a ring of four tetrahedral unit; potassium and sodium feldspar have three silicon tetrahedral and one aluminium tetrahedron, while in calcium feldspar half of four tetrahedral units are silicon-based and another half are aluminium-based [1]. The surface of feldspar is composed of positive and negative sites. The positive charges are mostly $\mathrm{Na}^{+}$ions in albite and $\mathrm{K}^{+}$ions in orthoclase, microcline, and the negatives are polar silanol groups or nonpolar siloxane group [2, 3].

The separation of feldspar from quartz is challenging due to their identical crystalline structures and close similarities in their physical and chemical properties. However, the only technique was recommended to obtain the feldspar was by flotation process. It can be related to the adsorption mechanism of the collector (reagent) onto feldspar surface.

Corresponding author at: Mineral Research Centre, Minerals and Geoscience

Dept. Malaysia, Jalan Sultan Azlan Shah, 31400 Ipoh, Perak, Malaysia

E-mail addresses: is.ibrahim@jmg.gov.my (Ismail Ibrahim)
The interaction between collector and mineral would be able to change the surface properties of feldspar from hydrophilic to hydrophobic. The floatability of feldspar is essentially determined by their surface state thus by the extent of surface free energy components of feldspar.

When feldspar and quartz are ground, their surfaces consist of silicon and aluminium atoms (for feldspar) and silicon (for quartz) are unsaturated due to anionic tetrahedron breakage. In a dry environment broken $\mathrm{SiO}$ bonds will result in reactive surface sites, on which atmospheric water molecules can chemisorb to cover the surface with hydroxyl group (silanol group) with hydroxyl group (silanol group). However when placed in water, the surface atoms are saturated with hydroxyl group and thus, the dissociation of surface hydroxyl $\mathrm{H}^{+}$or $\mathrm{OH}^{-}$at low and high $\mathrm{pH}$ respectively, creating either a positively or negatively charged surface [1, 3, 4 and 5]. The significant isoelectric point is the $\mathrm{pH}$ at which the zeta potential is zero [6]. There is a $\mathrm{pH}$ known as the point of zero charge (pzc), where the majority of surface sites are neutral and the net charge on the surface is zero (i.e the density of positive and negative sites is equal).

The flotation of feldspar from quartz has been the most suitable method for the separation process. In a 
conventional process, feldspar is separated from quartz using a cationic amine collector and hydrofluoric (HF) acid as an activator for feldspar. As it is known the process pollutes the environment and causes health problem, subsequently will result in the high cost to keep the environment friendly $[7,8]$. Therefore a mixed cationic and anionic collector N-Tallow 1,3 propylene-diamine-dioleate (duomeen TDO) was found to be effective for feldspar flotation without using HF acid [7, 9 and 10]. There were also studies being done on single mineral without using HF acid to obtain high recoveries of feldspar [11-14]. Another study was the flotation of feldspar from quartz using nalkyltrimethylene diamine together with sodium petroleum sulphonate as collectors in hydrochloric acid or sulfuric acid using FW type flotator with $400 \mathrm{ml}$ capacity at 10\% pulp [15].

This paper aims at evaluating feldspar behavior and its flotation process performance using mixed collector (cationic and anionic) namely $\mathrm{N}$ - tallow 1,3 propylene diamine-dioleate (duomeen TDO). Initial understanding of adsorption behavior of mixed collector cationic and anionic behavior is very significant that can provide guidance for manipulation of surface properties before the process can be further proceeded to the bench scale flotation. This was being done upon correlated data collected from several different fundamental measuring techniques such as zeta potential, FTIR, contact angle and Hallimond tube. On the other hand, chemical and physical properties of the sample were also investigated.

\section{EXPERIMENTAL}

\subsection{Sample preparation}

Samples of pegmatite rock were used in this experimental works were obtained from Apex Granite, Bukit Mor Quarry, Johore, Malaysia. At first the rock samples were dried, crushed using primary crusher and secondary crusher. Free feldspar and quartz were manually collected from the sample. Approximately 200 grams of each minerals were ground for 10 minutes in a laboratory ball mill with $10 \mathrm{~kg}$ of mixed steel balls $(5 \mathrm{~kg}$ of $5.0 \mathrm{~cm}, 3$ $\mathrm{kg}$ of $3.75 \mathrm{~cm}$ and $2 \mathrm{~kg}$ of $2.50 \mathrm{~cm}$ diameter). The ground minerals were screened to produce particle size fraction $-150+38 \mu \mathrm{m}$. The grinding process was repeated until sufficient sample was obtained. The particles were analyzed for contact angle measurement. And flotation test works using Hallimond. Some of the particles were further pulverized using agate mortar and sieved to $-5 \mu \mathrm{m}$ using ultrasonic bath. This fraction was then analyzed by zeta potential and FTIR analyses.

\subsection{Chemical reagent}

A mixed cationic-anionic diamine collector of $\mathrm{N}$ Tallow 1,3 propylene diamine dioleate (duomeen TDO) was used in the experimental works. Prior flotation process, duomeen TDO collector was dissolved in distilled water.
Analytical grade of sodium hydroxide was used for $\mathrm{pH}$ adjustment. Diluted Aero 65 was used as a frother.

\subsection{Sample Characterization}

X-ray fluorescence (XRF) was used to determine the total chemical composition of the sample. The Fe content was analyzed by atomic absorption spectrophotometer (AAS). Representative rock polish samples were observed using image analysis purposely to foresee its feldspar surface and iron stain. X-ray diffraction (XRD), field emission scanning electron microscope (FESEM) and energy dispersive $\mathrm{X}$-ray (EDX) were used to support the studies.

\subsection{Zeta potential measurements}

The objective for determining zeta potential was to obtain an indication of the magnitude of the potential at the beginning of the diffuse double layer around the particles. Electrokinetic properties such as potential determining ions (pdi) and isoelectric point (iep) in an aqueous of fine particles are very important factors in understanding the adsorption mechanism of organic and inorganic species at the solid and solution interface. To perform the zeta potential test, feldspar and quartz particles $-5 \mu \mathrm{m}$ were used at a concentration of $0.025 \mathrm{~g} / 100 \mathrm{ml}$. Ionic strengths of $10^{-3}$ $\mathrm{M}$ was maintained with $\mathrm{KNO}_{3}$. Solutions in the range of $\mathrm{pH} 2$ to $\mathrm{pH} 10$ were prepared and then the mineral was added. After 30 minutes conditioning, the $\mathrm{pH}$ of the suspension was recorded again and regarded as the $\mathrm{pH}$ of the measurement.

Zeta potential was determined using Brookhaven Zeta plus zeta meter (USA). The softwares allow the direct reading of zeta potential calculated from the electrophoretic velocity is proportional to the electric field, with the proportionality constant called the electrophoretic mobility using new approach which is shown in equations 1 and 2 $[16,17]$ :

$\overrightarrow{\mathrm{V}_{\mathrm{ep}}}=\mu_{\mathrm{ep}} \vec{E}$

where,

$\overrightarrow{\mathrm{V}}_{\mathrm{ep}}$ is electrophoretic velocity, $\vec{E}$ is the electric field strength and $\mu$ is Electrophoretic mobility

$\mu_{\mathrm{ep}}=\varepsilon_{\mathrm{r}} \varepsilon_{0} \zeta / \eta$

where $\mu_{\mathrm{ep}}$ is the electrophoretic mobility, $\varepsilon_{\mathrm{r}}$ is the relative permittivity of the liquid, $\zeta$ is Zeta potential and $\eta$ its viscosity.

\subsection{Contact angle and surface energy determination}

The critical surface tension of wetting of a mineral was determined by contact angle approach. Surface tension 
and surface free energy are important parameters in flotation because it quantifies the disruption of intermolecular bonds that occurs when a surface is created. Since feldspar and quartz are hydrophilic, if their surfaces are covered with a hydrophobic reagent meaning that its total surface energy would be reduced, so that they can attach to the bubble and rise to the top of the froth zone. Contact angle together with collector adsorption, is a major indicator for identifying the surface energy of a material. To perform the contact angle test, 1.5 gram of solid powder of samples of $-150+38 \mu \mathrm{m}$ size fraction each was being conditioned in $100 \mathrm{ml}$ solution for 30 minutes with duomeen TDO at different $\mathrm{pH}$. Then the solution was filtered, the residue obtained was dried and 1 gram each was placed into a glass tube and was carefully and equally packed each time.

Contact angle on solid powders was determined by sorption measurements using Kruss Tensiometer K100 and Kruss LabDesk 3.1 software. Sorption measurements using rise of liquids in powder pores as in capillary tubes applying the Washburn equation [18]:

$\mathrm{I}^{2} / \mathrm{T}=\gamma_{1}^{\mathrm{r} \cdot \cos \Theta} / 2 \eta$

Here I represents the mass of the liquid flow, $\gamma_{1}$ is the surface tension of liquid, $r$ is the rise the capillary radius, $\eta$ is the liquid viscosity and $\Theta$ is advancing angle. Modifying the equation by replacing the capillary radius by a capillary constant, the contact angle can be calculated. The capillary constant was determined using $n$-Hexane with virtual $0^{\circ}$ angle, giving a $\cos \theta=1$. Using the obtained capillary constant, contact angles for three standard liquids used: deionised water, 1-bromonaphtalene and formamide were calculated with defined acid and base components. This is followed by surface energy estimation with van Oss acidbase method. The free surface can be separated into a polar or dispersion component (due to Lifshitz-van-der Waals forces) and a polar or Lewis acid-base component comprising an electron-donor and electron-acceptor parameter of the interacting phases [19].

The surface free energy can be derived from contact angle $(\Theta)$ measurements. According to van Oss [19], the free surface can be separated into a polar or dispersion component (due to Lifshitz-van-der Waals forces) and a polar or Lewis acid-base component comprising an electron-donor and electron-acceptor parameter of the interacting phases:

$\gamma^{\mathrm{AB}}=2 \sqrt{ } \gamma^{+} \gamma$

$\gamma_{\mathrm{sl}}=\gamma_{\mathrm{s}}+\gamma_{1}-2\left(\sqrt{ } \gamma_{\mathrm{s}}^{\mathrm{LW}} \gamma_{\mathrm{l}}^{\mathrm{LW}}+\sqrt{ } \gamma_{\mathrm{s}}^{+} \gamma_{1}^{-}+\sqrt{ } \gamma_{\mathrm{s}}^{-} \gamma_{1}^{+}\right)$

The following equation is obtained while combining Young's equation with 4 and 5:

$(1+\cos \theta) \gamma_{1=2}\left(\sqrt{ } \gamma_{s}^{\mathrm{LW}} \gamma_{1}^{\mathrm{LW}}+\sqrt{ } \gamma_{\mathrm{s}}^{+} \gamma_{1}^{-}+\sqrt{ }{\gamma_{\mathrm{s}}}^{-} \gamma_{1}^{+}\right)$

The values of Lifshitz-van der Waals $\left(\gamma_{s}{ }^{\mathrm{LW}}\right)$, Lewis electron-donor $\left(\gamma_{\mathrm{s}}^{-}\right)$, and Lewis electron-acceptor $\left(\gamma_{\mathrm{s}}^{+}\right)$ components of the free surface energy on the feldspar and quartz with untreated and varying amounts of propylenediamine TDO were calculated using equation 6 . By measuring contact angles at least with three different liquids such as deionized water, bromonapthalene and formamide with defined acid and base components, the surface energies of minerals could be determined.

\subsection{FTIR measurement}

Fourier transformed infrared (FTIR) spectroscopy is a measurement technique for collecting infrared spectra and hence the chemical bonds in a molecule can be determined. Since the collector used was TDO Duomeen, the relative adsorption of this collector on feldspar and quartz were accessed by the intensity of the adsorption band. Thus the alkyl band characteristic, $v_{\text {as }}\left(\mathrm{CH}_{3}\right), v_{\mathrm{as}}\left(\mathrm{CH}_{2}\right)$ and $v_{\mathrm{s}}\left(\mathrm{CH}_{2}\right)$ as well as amine spectrum due to $v_{\text {as }}\left(\mathrm{NH}_{2}\right)$ and $v_{\mathrm{s}}\left(\mathrm{NH}_{2}\right)$ could be determined. At the same time the area under the alkyl chain can be measured. To perform the FTIR test, $0.1 \mathrm{~g}$ of the mineral powder $(-5 \mu \mathrm{m})$ was conditioned in an Erlenmeyer flask containing $100 \mathrm{ml}$ collector solution at specified $\mathrm{pH}$ and concentration for 60 minutes [8]. After equilibration, the suspension was filtered through millipore filter paper and the solids were air-dried overnight at room temperature. The FTIR spectras were obtained with Perkin Elmer Spectrum One, an average of 400 scans measured at $4 \mathrm{~cm}^{-1}$ resolution with narrow band. The samples were mixed with $\mathrm{KBr}$ matrix.

\subsection{Single mineral flotation}

The Hallimond tube flotation tests for feldspar and quartz at $\mathrm{pH} 2$ with different dosage of collector. The performance of the flotation was measured based on the recovery of a single mineral. $\mathrm{pH}$ was control by sulfuric acid $\left(\mathrm{H}_{2} \mathrm{SO}_{4}\right)$ and $\mathrm{NaOH}$ as $\mathrm{pH}$ controllers. Prior flotation $250 \mathrm{ml}$ of collector solution was prepared in a beaker and agititate by magnetic stirrer. The solution was then transfered into the Hallimond Tube and 1 gram of the mineral was then added. The suspension was conditioned for five minutes folowed by flotation for 1 minute at a constant air flowrate of $10 \mathrm{ml} / \mathrm{min}$. When flotation time was done, the air flow and stirrer was stopped. Float product was filtered, dried and weighed. The weigh of product obtained will be divided by $1 \mathrm{~g}$ and multiplied by 100 to get percent of recovery.

\section{RESULTS AND DISCUSSION}

\subsection{Sample characterization}

Table 1.0 shows the chemical composition of pegmatite and feldspar sample used in the experimental works. It can be seen that the percentage of $\mathrm{K}_{2} \mathrm{O}$ was significant compared to $\mathrm{Na}_{2} \mathrm{O}$ and this indicated that the sample was alkali feldspar. 
The mineral identification using $\mathrm{XRD}$ as shown in Figure 1 demonstrated that the major mineral present in pegmatite sample were quartz, microcline and albite. Figure 2 shows the FESEM micrograph indicated that the quartz particles disseminated in feldspar. The analysis was carried out on rock polish section that previously being etched by hydrofluoric acid at $49 \%$ concentration. Hence, the quartz particle was measured approximately between 10-30 $\mu \mathrm{m}$ wide and 20 to $130 \mu \mathrm{m}$ long. Figure 3 (a) and (b) show the EDAX analysis for feldspar and interlocked quartz respectively, where the feldspar contained elements Al (10.03\%), Si (26.18\%), K (10.13\%), Na (2.61\%) and O (55.72\%) while the quartz showed the presence of $\mathrm{Si}$ (45.12\%) and O (52.32\%).

Table 1.0 the chemical composition of pegmatite and feldspar sample

\begin{tabular}{|c|c|}
\hline Chemical Composition & Feldspar (\%) \\
\hline $\mathrm{SiO}_{2}$ & 68.50 \\
\hline $\mathrm{Al}_{2} \mathrm{O}_{3}$ & 17.48 \\
\hline $\mathrm{Na}_{2} \mathrm{O}$ & 2.66 \\
\hline $\mathrm{K}_{2} \mathrm{O}$ & 11.20 \\
\hline $\mathrm{Fe}_{2} \mathrm{O}_{3}$ & 0.11 \\
\hline $\mathrm{CaO}$ & 0.16 \\
\hline
\end{tabular}

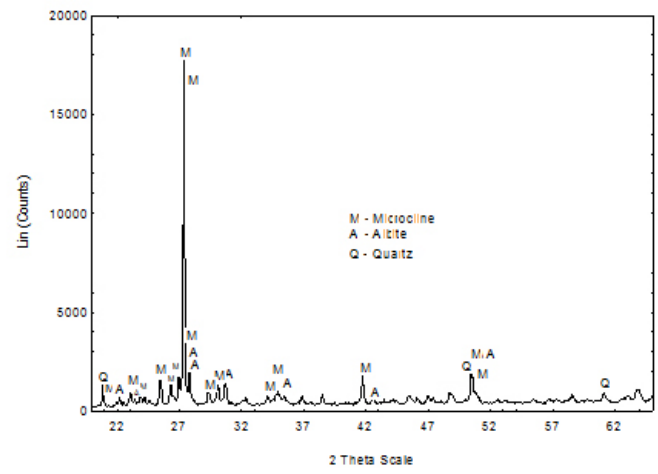

Fig. 1 XRD analysis of pegmatite was identified to be quartz, microcline and albite.

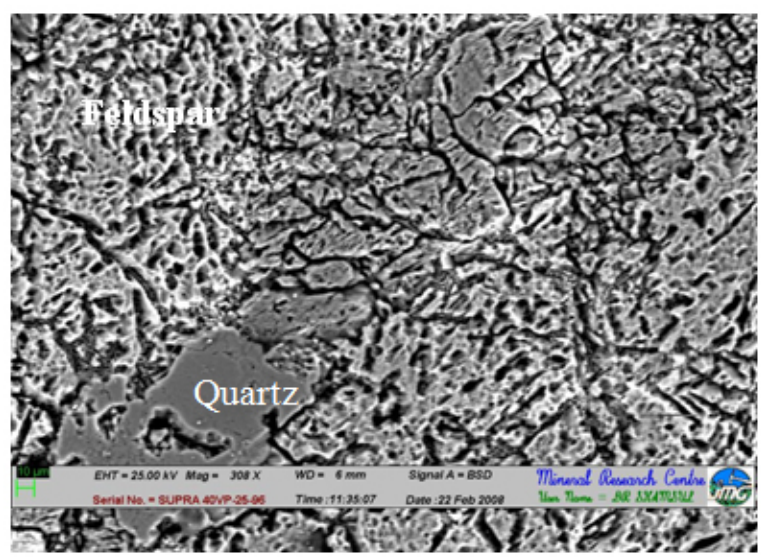

Fig. 2 FESEM micrograph shows the quartz disseminated in feldspar.
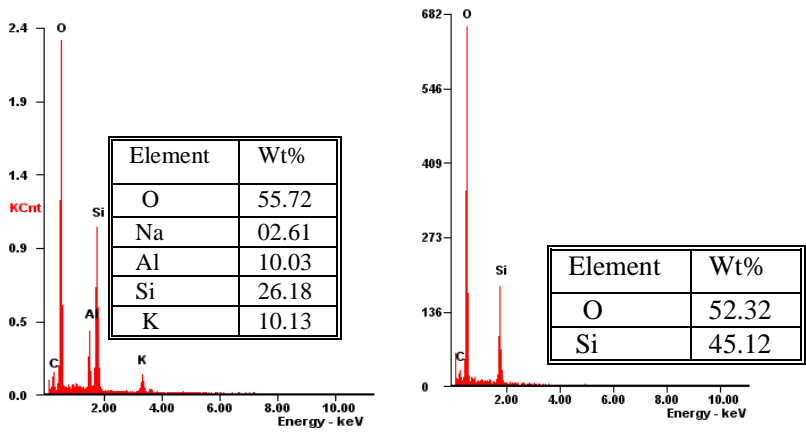

Fig. 3 EDAX spectrum of (a) feldspar and (b) quartz

\subsection{Zeta Potential Measurements}

Figure 4 illustrates the effect of $\mathrm{pH}$ on zeta potential of feldspar and quartz. It can be seen that an increase of $\mathrm{pH}$ in suspension resulted in an increasing in the negative charge of both samples until $\mathrm{pH} 10$. The results showed that the isoelectric point (iep) of quartz was at pH 2 while the extrapolation of the curves in the case of feldspar indicated iep of about $\mathrm{pH}$ 1.90. At $\mathrm{pH} 2$, feldspar exhibited $-7.89 \mathrm{mV}$ whereas quartz approximately $0.00 \mathrm{mV}$. In general feldspar showed higher negative at all $\mathrm{pH}$ charge compared to quartz.

The zeta potential of feldspar and quartz as a function of duomeen TDO concentration at $\mathrm{pH} 2$ is shown in Figure 5. The zeta potential for feldspar started at lower concentration of Duomeen TDO (2 ppm) gave $-1.0 \mathrm{mV}$. However, the magnitude of charge reversal for feldspar occurred at $10 \mathrm{ppm}$, then the feldspar acquired drastically increasing positive charge until about $35.02 \mathrm{mV}$ at $60 \mathrm{ppm}$ duomeen TDO. Whereas for quartz, at $2 \mathrm{ppm}$ duomeen TDO the zeta potential obtained was $-3 \mathrm{mV}$. Then the zeta potential of quartz increased gradually until $13.28 \mathrm{mV}$ at 60 ppm TDO, and above this dosage its zeta potential remained

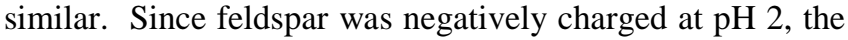
doubly charged positive diamine species adsorbed through electrostatic interactions leading to its flotation but not adsorbed on quartz due to zero charge. The adsorption principally occurred was due to duomeen TDO which is a compound consists of reacting one molecule of alkyl (tallow) propylene diamine [R-NH- $\mathrm{CH}_{2}-\mathrm{CH}_{2}-\mathrm{CH}_{2}-\mathrm{NH}_{2}$ ] and two molecules of oleic acid $\left[\mathrm{CH}_{3}\left(\mathrm{CH}_{2}\right)_{7} \mathrm{CH}=\mathrm{CH}-\right.$ $\left(\mathrm{CH}_{2}\right)_{7} \mathrm{COOH}$. To yield di-oleate salt, the structural formula [R-NH$\left.-\mathrm{CH}_{2}-\mathrm{CH}_{2}-\mathrm{CH}_{2}-\mathrm{NH}_{3}\right)^{++} 2\left(\mathrm{C}_{17} \mathrm{H}_{33} \mathrm{COO}\right)^{-}$is formed [9]. The diamine and oleate molecules forming the diamine-dioleate compound could be due to hydrogen bonding involving two electronegative atoms of $\mathrm{O}$ and $\mathrm{N}$ of the respective functional groups which can be shown as [20]:

$\equiv \mathrm{SiOH} \ldots . \mathrm{H}_{2} \mathrm{~N}-\mathrm{R} \leftrightarrow \equiv \mathrm{SiO}^{-} \ldots \mathrm{H}_{3}^{+} \mathrm{N}-\mathrm{R}$

Where negative charges $\left(\mathrm{SiO}^{-}\right)$exist on the feldspar surfaces. 


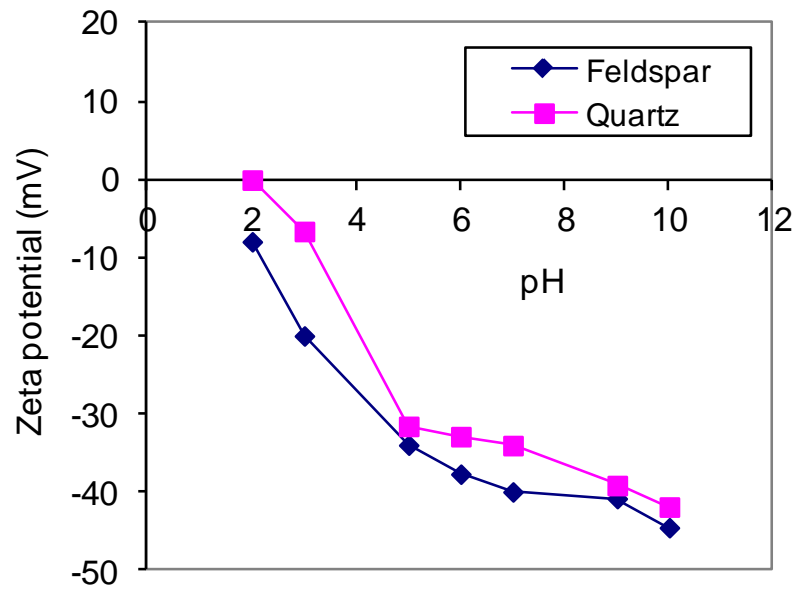

Fig. 4 Effect of $\mathrm{pH}$ on zeta potential for feldspar and quartz.

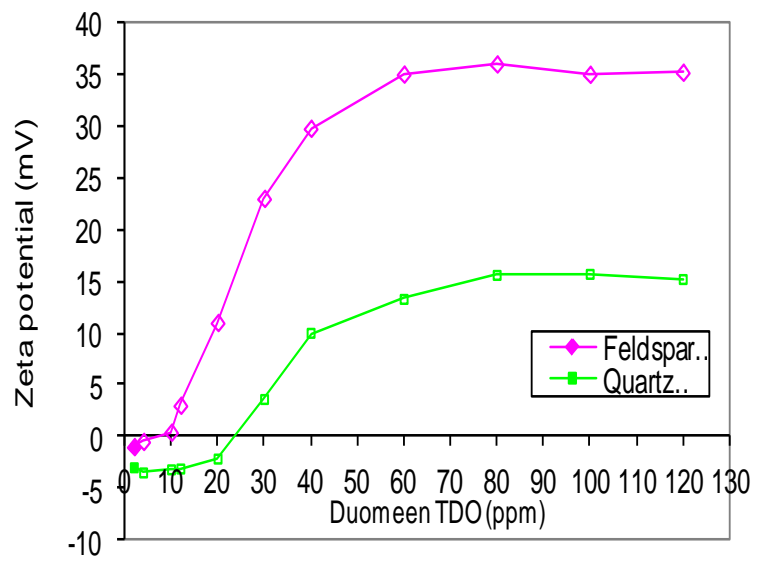

Fig.5 Zeta potential of feldspar and quartz as a function of Duomeen TDO concentration at $\mathrm{DH} 2$.

\subsection{Contact Angle Measurements}

Contact angle, together with collector adsorption, is a major indicator for identifying whether flotation conditions are capable in separating minerals. As can be seen in Table 2, the contact angle increased with the increasing in the duomeen TDO concentration. It is known that the hydrophilic surface character of a mineral can be changed to a hydrophobic state by adsorbed surface active material. The contact angles $\left(\Theta_{\text {water }}\right)$ of untreated feldspar and quartz were as $60.15^{\circ}$ and $57.00^{\circ}$ respectively. The overall contact angles $\left(\Theta_{\text {water }}\right.$ for feldspar was higher than quartz after treating with duomeen TDO at $\mathrm{pH} 2$. This was more pronounced when the collector used was $1.2 \mathrm{ppm}$ giving contact angles $\Theta_{\text {water }}$ feldspar $90.0^{\circ}$ which was higher than quartz $85.58^{\circ}$. When the contact angle of feldspar reached to $90^{\circ}$ at $1.20 \mathrm{ppm}$ of duomeen TDO, signifying that formation of monolayer around the particles was formed and the monolayer of quartz reached at $1.4 \mathrm{ppm}$ of duomeen TDO usage.
Table 2 Contact angle values of feldspar and quartz with duomeen TDO adsorption.

\begin{tabular}{|c|c|c|c|c|}
\hline \multirow[t]{2}{*}{ Minerals } & \multirow{2}{*}{$\begin{array}{l}\text { Treatment with } \\
\text { Duomeen TDO } \\
(\mathrm{ppm})\end{array}$} & \multicolumn{3}{|c|}{ Contact angle $\left({ }^{\circ}\right)$} \\
\hline & & $\Theta_{\text {water }}$ & $\Theta_{\text {bromonapth }}$ & $\Theta_{\text {formamide }}$ \\
\hline \multirow{8}{*}{ Felspar } & Untreated & 60.15 & 37.13 & 50.00 \\
\hline & 0.2 & 62.45 & 37.50 & 51.00 \\
\hline & 0.4 & 72.10 & 46.16 & 58.00 \\
\hline & 0.6 & 76.21 & 47.40 & 60.0 \\
\hline & 0.8 & 78.30 & 48.00 & 61.90 \\
\hline & 1.0 & 85.22 & 52.16 & 63.54 \\
\hline & 1.2 & 90.00 & 55.0 & 65.50 \\
\hline & 1.4 & 90.00 & 57.00 & 67.37 \\
\hline \multirow{8}{*}{ Quartz } & Untreated & 57.00 & 29.73 & 46.37 \\
\hline & 0.2 & 59.47 & 35.10 & 51.00 \\
\hline & 0.4 & 62.00 & 37.10 & 53.00 \\
\hline & 0.6 & 68.32 & 43.57 & 55.00 \\
\hline & 0.8 & 78.32 & 45.43 & 57.23 \\
\hline & 1.0 & 80.45 & 46.00 & 60.00 \\
\hline & 1.2 & 85.58 & 47.32 & 62.22 \\
\hline & 1.4 & 90.00 & 50.32 & 65.14 \\
\hline
\end{tabular}

Table 3 Calculated surface free energies and components of Feldspar and quartz with duomeen TDO adsorption together with interface energies $\left(\mathrm{mJ} / \mathrm{m}^{2}\right)$.

\begin{tabular}{|c|c|c|c|c|c|c|}
\hline $\begin{array}{l}\text { Min- } \\
\text { ral }\end{array}$ & $\begin{array}{l}\text { Treatment } \\
\text { with } \\
\text { duomeen } \\
\text { TDO } \\
(\mathrm{ppm}) \\
\end{array}$ & $\begin{array}{c}\gamma_{\mathrm{s}} \\
(\mathrm{ST}) \\
\mathrm{mJ} / \mathrm{m}^{2}\end{array}$ & $\begin{array}{l}\gamma_{\mathrm{s}}{ }^{\mathrm{LW}} \\
\text { (disperse } \\
\mathrm{p} \text { ) } \\
\mathrm{mJ} / \mathrm{m}^{2}\end{array}$ & $\begin{array}{l}\gamma_{\mathrm{s}}^{\mathrm{AB}} \\
\text { (polar } \\
\mathrm{p} \text { ) } \\
\mathrm{mJ} / \mathrm{m}^{2}\end{array}$ & $\begin{array}{l}\gamma_{\mathrm{s}}^{+} \\
(\operatorname{acid} \mathrm{p}) \\
\mathrm{mJ} / \mathrm{m}^{2}\end{array}$ & $\begin{array}{l}\gamma_{\mathrm{s}}^{-} \\
\text {(base } \\
\mathrm{p} \text { ) } \\
\mathrm{mJ} / \mathrm{m}^{2} \\
\end{array}$ \\
\hline \multirow{8}{*}{$\begin{array}{l}\mathrm{F} \\
\mathrm{e} \\
\mathrm{l} \\
\mathrm{d} \\
\mathrm{s} \\
\mathrm{p} \\
\mathrm{a} \\
\mathrm{r}\end{array}$} & Untreated & 40.43 & 36.02 & 4.42 & 0.21 & 22.91 \\
\hline & 0.2 & 40.15 & 35.86 & 4.29 & 0.22 & 20.54 \\
\hline & 0.4 & 36.07 & 32.02 & 4.05 & 0.31 & 13.31 \\
\hline & 0.6 & 35.11 & 31.35 & 3.76 & 0.36 & 9.94 \\
\hline & 0.8 & 34.22 & 31.07 & 3.15 & 0.28 & 8.94 \\
\hline & 1.0 & 32.35 & 29.03 & 3.33 & 0.70 & 3.97 \\
\hline & 1.2 & 30.29 & 27.61 & 2.68 & 0.95 & 1.90 \\
\hline & 1.4 & 29.36 & 26.60 & 2.76 & 0.79 & 2.40 \\
\hline \multirow{8}{*}{$\begin{array}{l}\mathrm{Q} \\
\mathrm{u} \\
\mathrm{a} \\
\mathrm{r} \\
\mathrm{t} \\
\mathrm{z}\end{array}$} & Untreated & 42.90 & 38.92 & 3.97 & 0.16 & 24.65 \\
\hline & 0.2 & 39.71 & 36.90 & 2.81 & 0.08 & 24.71 \\
\hline & 0.4 & 38.67 & 36.07 & 2.60 & 0.07 & 22.72 \\
\hline & 0.6 & 37.77 & 33.16 & 4.61 & 0.34 & 15.73 \\
\hline & 0.8 & 36.81 & 32.49 & 4.32 & 0.72 & 6.50 \\
\hline & 1.0 & 35.49 & 32.02 & 3.47 & 0.49 & 6.10 \\
\hline & 1.2 & 34.21 & 31.39 & 2.82 & 0.60 & 3.33 \\
\hline & 1.4 & 32.08 & 29.93 & 2.15 & 0.62 & 1.85 \\
\hline
\end{tabular}

The results shown in Table 3 with the values of $\gamma^{\mathrm{AB}}=2 \sqrt{ } \gamma^{+} \gamma^{-}$ , $\gamma_{\mathrm{s}}$ was used to calculate the surface free energy components. It shows that both feldspar and quartz exhibited a significant decreased in free energy and its components with increasing duomeen TDO dosage leading to enhance hydrophobicity. The $\gamma_{\mathrm{s}}$ value of untreated feldspar decreased from 40.43 to $29.36 \mathrm{~mJ} / \mathrm{m}^{2}$ at duomeen concentration of $1.4 \mathrm{ppm}$, while for quartz have shown the decreasing of $\gamma_{\mathrm{s}}$; from 42.90 to $32.08 \mathrm{~mJ} / \mathrm{m}^{2}$. The polar (acid-base) component $\gamma_{\mathrm{s}}^{\mathrm{AB}}$, which was representing the surface free energy of feldspar and quartz, decreased with increasing hydrophobicity due to the replacement of surface polar groups by nonpolar groups that carry low or permanent dipoles. 


\subsection{FTIR measurement}

To investigate the effect of duomeen TDO dosage on feldspar and quartz, two set of experiments were performed in which the pulp were subjected to $\mathrm{pH} 2$. The adsorption plot of the peaks for feldspar and quartz are illustrated in Figures 6 and 7 respectively. The FTIR spectra of feldspar and quartz treated with $100 \mathrm{ppm}$ duomeen TDO showed the bands characteristic of alkyl chains, $y_{\text {as }}\left(\mathrm{CH}_{3}\right), \quad y_{\text {as }}\left(\mathrm{CH}_{2}\right)$ and $y_{\mathrm{s}}\left(\mathrm{CH}_{2}\right)$ groups between region $3000-2800 \mathrm{~cm}^{-1}$, at around $2955 \mathrm{~cm}^{-1}, 2926$ and $2854 \mathrm{~cm}^{-1}$.

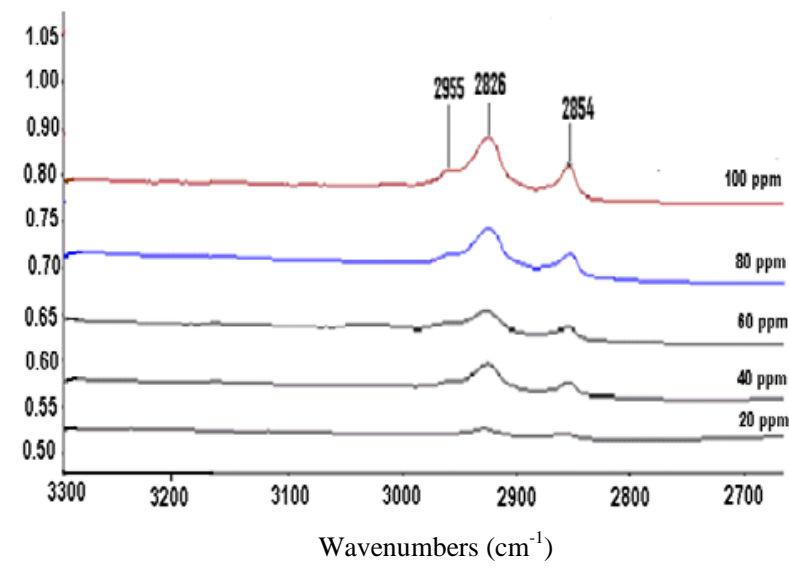

Fig. 6 Adsorption of duomeen TDO on feldspar at different concentrations.

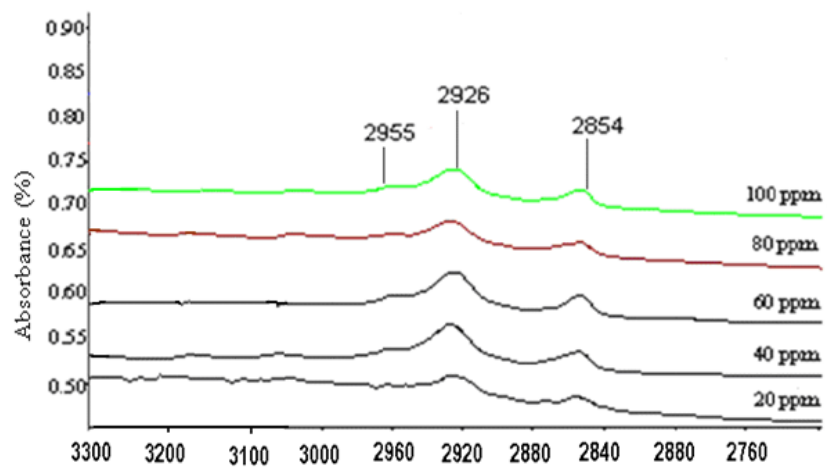

Wavenumbers $\left(\mathrm{cm}^{-1}\right)$

Fig. 7 Adsorption of duomeen TDO on quartz at different concentrations.

The intensity of the alkyl chain bands increased slightly higher for feldspar compared to quartz with increasing initial duomeen TDO concentration, emphasising more collector adsorption on feldspar. The peak area under the alkyl chain bands between region $3000-2800 \mathrm{~cm}^{-1}$ was measured and plotted as a function of concentration as shown in Fig 8. It is assummed that since the zero potential charge (zpc) for quartz was found to be 2, the duomeen TDO adsorption at this $\mathrm{pH}$ on quartz was also lower.

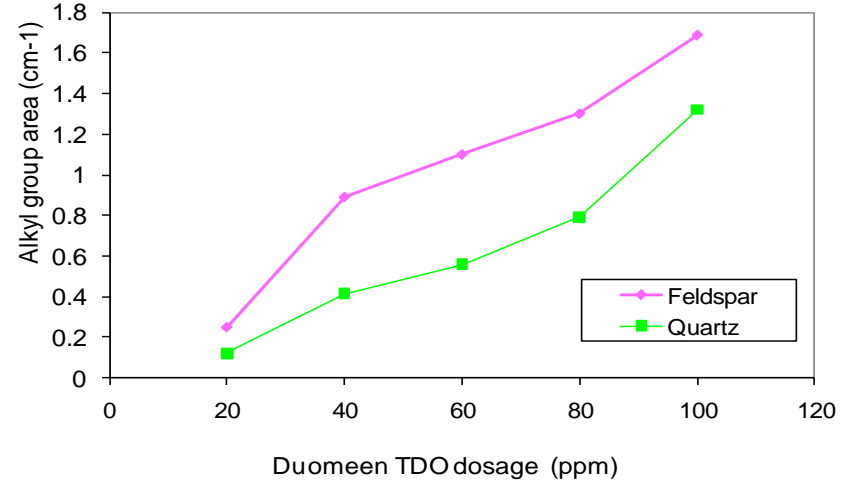

Fig. 8 Area under alkyl chain bands (3000-2800 $\left.\mathrm{cm}^{-1}\right)$ of spectra

\subsection{Single mineral flotation}

The flotation of feldspar and quartz response differently by adding different dosage of duomeen TDO at $\mathrm{pH} 2$ with sulfuric acid as $\mathrm{pH}$ controller is shown in Figure 9. In general the feldspar recovery increased with the increasing of duomeen TDO concentration. Feldspar floated more effectively compared to quartz which floated in lesser amount. Thus, the flotation of feldspar however started to occur at very low concentration of duomeen TDO $(0.8 \mathrm{ppm})$ with $28 \%$ floated and increased gradually to $40.12 \%$ at $20 \mathrm{ppm}$ duomeen TDO, then its recovery rose to $86.0 \%$ at $60 \mathrm{ppm}$ duomeen TDO. Above this point the feldspar recovery remained similar.

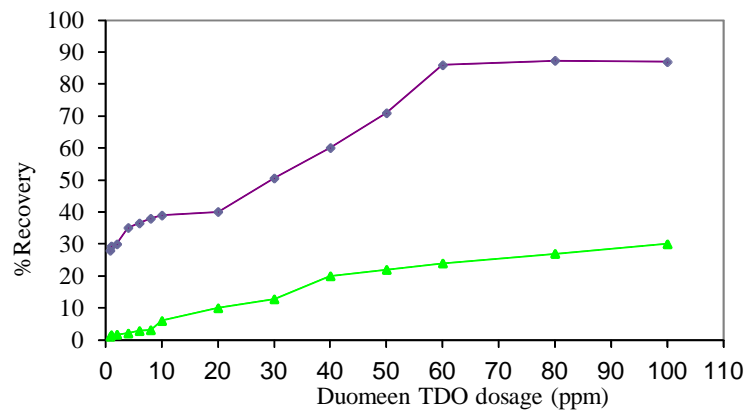

Fig. 9 Recovery of feldspar and quartz as a function of duomeen TDO dosage at $\mathrm{pH} 2$.

\section{CONCLUSION}

The zeta potentials at $\mathrm{pH} 2$ without treating duomeen TDO showed the magnitude of $\mathrm{mV}$ for quartz approximately 0 compared to feldspar $-7.89 \mathrm{mV}$ which was marginally higher. This $\mathrm{pH}$ was used for Hallimond tube flotation. Monolayer of duomeen TDO was developed on the feldspar particle when $1.2 \mathrm{ppm}$ of the collector used at $\mathrm{pH} 2$. This was indicated by the contact angle of water $\Theta_{\text {water }}$ $=90^{\circ}$. FTIR measurements have shown that the spectra of 
duomeen TDO exhibit as alkyl chains and the adsorption of this collector on feldspar was higher than quartz. Feldspar floatability by single mineral flotation increased with increasing concentration of duomeen TDO.

\section{ACKNOWLEDGEMENTS}

The authors would like to thank and also pleased to acknowledge the support (i) Director of Mineral Research Centre and fellow staffs of the Centre especially to the staffs of Metallurgy Section for their assistance of this research can be carried-out successfully. (ii) USM Engineering Campus for technical assistance in the research study. (iii) Ministry of Natural Resources and Environmental, Malaysia for funding the project. (iv) Research group of Dept of Chemical Engineering and Geosciences, Luleå University of Technology, Sweden headed by Prof K. Hanumantha Rao for assistance on fundamental study of feldspar flotation.

\section{REFERENCES}

G.J. Graveling, K.V. Ragnarsdotirr, G.C. Allen, J. Eastman, P.V. Brady, S.D. Balsley, and D.R. Skuse, Geochimimica et Cosmochimia Acta, 61 (1997) 3515-3523.

C. Demir, I.Bentli, I. Gulgönul \& M.S Celik, Minerals Engineering, 16 (2003) 551-554.

C. Karaguzel, M.F. Can, E. Sonmez, M.S. Celik, Journal of Colloid and Interface Science, 285 (2005) 192-200.

H.K. Rao, and K.S.E. Forssberg, In: A. Gash, Pradip and Kumar, R., 1995. Editors, Selected Topics Mineral Processing City Press, Baltimore (1995) 86.

M. Alkan, ö, Demiirbas, and M. Dogan, Microporous and Microporous Materials, 83 (2005) 51-59

G.V. Franks and L. Meagher, Colloids and Furface A: Physicochemical and Engineering Aspects, 16 (2003) 1279-1284.

A.Viyadhar, H.K. Rao and K.S.E. Forssberg, Journal of Colloid and Interface Science, 248 (2002) 19-29.

B. Oteyaka, Y. Ucbas, K. Bilir, H. Gursoy, R. Bozkurt and M. Ciftci, In: G. Ozbayoglu, C. Hosten, M.U. Atalay, C. Hicyilmaz and A.I. Arol, Editors, Mineral Processing on the Verge of the 21st Century, Balkema, Rotterdam (2000) 323-326.

S.G. Malghan, SME Fall Meeting, Denver, Colorado, (1976).

[10] S.G. Malghan, Min. Eng. 33, 1616 (1981).

[11] J. Tang, B. Sun, Z. Cheng, X. Chen, H.Zao and S. Zhang, Proc. XVIII Int. Miner. Process. Congr., Parkville, Aust.Inst.Min. Metall., 4 (1993) 851.

[12] H.K. Rao and K.S.E. Forsberg, Proc. XVIII Int. Miner. Process., Parkville, Aust. Inst. Min. Metall., 4 (1993) 837.

[13] Y. Liu, H. Gong, J. Qiu and K. Zhang, Proc. XVIII Int. Miner. Process., Parkville, Aust. Inst. Min. Metall., 4 (1993) 857.

[14] El M.S. Salmawy, E.Kusaka and T.Wakamatsu, Proc. XXI INT. Miner. Prcess.Congr., Elsevier Amsterdam, B (2000) B8b-160.

[15] J. Shimoiizaka, T.Nakatsuka, and T. Katayanagi, World Mining and Metals Technology (A.Weiss, Ed.), 1 Port City Press, Baltimore (1976) 423.

[16] Mc Fadyen, P. and Fairhurst, D. Zeta potentials of nanoceramic materials measurement and interpretation. A paper presented at the Canadian Mineral Analyst Meeting, held in Winipeg, Manitoba, Canada (1993).

[17] Bruce, B.W., Walter, W.T. and David, F. Zeta potential: A new approach., A paper presented at the Canadian Mineral Analysts Meeting, Winnipeg, Manitoba, Canada (1993).

[18] E.W. Washburn, Phys.rev.II (3), full text via CrossRef, (1921) 273.

[19] C.J. Van Oss, Interface Forces in Aqueous Media, Dekker, New York, (1994).

[20] H.K. Rao, and A. Viyadhar, Journal of Colloid and Interface Science, 306 (2007) 195-204. 